\title{
Memorization of Piano Music: A Challenge for Chinese Piano Students
}

\author{
Ruoxu Chen ${ }^{1}$ \\ ${ }^{1}$ College of Music, Southwest University, Chongqing, China \\ Correspondence: Ruoxu Chen, College of Music, Southwest University, Chongqing, China. E-mail: \\ 461095789@qq.com
}

Received: December 12, 2015 Accepted: January 8, 2016 Online Published: February 23, 2016

doi:10.5539/ass.v12n3p112

URL: http://dx.doi.org/10.5539/ass.v12n3p112

\begin{abstract}
As many Chinese piano students have encountered various kinds of problem to memorize the music, which negatively influences their musical development, this paper reports a comprehensive study on the memorization of piano music and introduces the efficient ways to accomplish the memorization. Correlative analysis demonstrate that 1) like any other ability, the ability to memorize piano music needs a lot of practice; 2) for pianists who are making great efforts to fulfill their inevitable memorization task, it is important to persistently have a positive attitude towards the goal through the entire memorizing process; 3) rather than regarding memorization as a time-consuming and must-do tradition that has been handed down from the piano predecessors, it is more reasonable to regard the memorization process as an opportunity to wholly free the performers from the written page and to truly own the piece. Hopefully, this study can provide some assistance to both Chinese piano teachers and students to conquer the issue.
\end{abstract}

Keywords: piano memorization, performance, pedagogy, mental pressure

\section{Introduction}

In China today, piano is surely the most popular western instrument that steps into numerous Chinese families. Under the influence of rising Chinese piano stars such as LangLang and Yundi Li, more and more piano students are fascinated with piano playing and dream to become a concert pianist. However, for many Chinese piano students, including both amateur and professional, memorization of the music is always a difficult task which evokes nervousness and anxiety. Understanding the correct and efficient ways to memorize the piano music is an indispensable must-do for the piano students before they can achieve their music accomplishment.

As a matter of fact, the subject of memorization of piano music has become a controversial topic in the pedagogic piano domain, which triggered and continues to trigger a stir among pianists and piano teachers with two opposing sides either making arguments for or against memorization. Some believe that the effort contributed to accomplish memorization does not warrant pianist the security and confidence, while others think that the advantages of memorization provide enough incentive to pianists to stay stimulated and eventually fulfill the feats of memorization. Despite the fact that memorizing piano music is quite challenging and demands consistent discipline of mental intelligence, it is noticeable that pianists and piano teachers are more likely to advocate piano memorization rather than disputing against it. Additionally, this music tradition of memorization for piano playing has never changed in the last century.

Before getting into the depth of this topic, there are two questions that might be asked: is memorization required of pianists, and if so, how might the piano teachers prepare their students for the challenges of memorization? Understanding the purpose, function, and types of memorizing could better equip teachers to instruct their students on how to memorize.

\section{Reasons for Memorization}

One should ask himself/herself why they memorize our music. Does memorization provide the most freedom to express the beauty of the music? Does the audience notice a difference in the emotional connection between a memorized performance and one that uses the music? If both of those are true, are the benefits of those factors substantial enough to outweigh the effort that it takes to memorize a piece (Williamon, 1999)? There is a divide in the piano field over the outcome of this conflict. Some believe that the effort of the memorization process is too much to warrant the strain, whereas others think that the benefits of memorization provide enough incentive to accomplish the feats of memorization. It is important to understand in what circumstances pianists are 
expected to memorize their music, so that we can teach our students the reasons for memorization.

The skill of memorization is one that is often required of pianists. Competitive events, schools and concert audiences expect that a pianist's performances to be memorized. The tradition of memorizing concerts began with Franz Liszt and Clara Schumann in the $19^{\text {th }}$ Century, and it has not begun to release its grasp on the piano world until quite recently. With the onset of avant guard music being performed in concerts and competitions has caused the line to blur between the two viewpoints. Due to the difficulty and unfamiliarity of the form, motives, and compositional process, competitions have allowed the use of music during performance. This has made Montparker (1998), and those who follow her view point, feel more justified in their claim.

There exists a school of thought that believes that memorization is a waste a performer's energy, because the arduous effort it takes to memorize a piece outweighs the benefits one might gain from playing from memory. Some believe that performing with the music can aid in the expression of a piece, because the performer is not spending their energy worrying about memory slips. Having a copy of the music available during the performance can serve as a fail-safe for the performer (Montparker, 1998). However, not all musicians share the view that memorization should be removed completely from a pianist's world.

Those who support memorization believe that it offers the freest expression of emotion and the closest connection with the audience. Williamon (1999) performed a study to find if audiences perceived a stronger emotive response in those performances that were memorized, as it compared to those performances that were played with the music. He found that the audience was more emotionally drawn into those performances that were memorized. Furthermore, the audience members who had some experience in music found the emotive differences to be far more extreme. Though this study was done using a cellist playing solo repertoire, one could apply these findings to other areas of performance, including piano performance. Since those audiences tended to value those performances that were memorized, we could prepare our students for that environment. Knowledge of the memorization process and the types of memory should help teach our students how to memorize.

\section{Memorization Process}

"Memory is one of the technical requisites of the pianist, but in itself it has as little to do with art as having fleet fingers and supple wrists" (Hughes, 1915). Memorization is defined as the ability to define, store and recall information. The types of memorization that pianists use are procedural, memory that is related to a specific kinesthetic movement, and declarative, which is memory directly related to information (Anderson, 1976). Though memory is considered a single event by many who practice it, it actually consists of a variety of components. Of these components, only one, auditory, or aural, memory is used consistently in music. Auditory memory consists of three processes: echoic memory and early processing, short-term memory, and long-term memory. The parts of the diagram (Appendix) represent different processes, not places within the mind. Echoic memory consists of the individual acoustic vibrations and is considered a sensation, which lasts no longer than a second. Early processing consists of two parts, feature extraction and perceptual binding. Feature extraction includes the encoding of individual acoustical features of the sensation experienced during the echoic memory process. The perceptual binding process binds the features in the previous process together into separate, recognizable memory events (Snyder, 2000).

Once the events have been bound together, the mind categorizes them into chunks, which are then stored in the short-term memory. After the short-term chunks are rehearsed following the binding stage, the information moves from the short-term memory into the long-term memory. Ebbinghaus found that the longer the length of time that lapses between the initial memory event and the following rehearsals, the more information is forgotten. For students, the practical application of this "forgetting curve" is that one should immediately rehearse a memory after its initial exposure to minimize the loss of information (Aiello \& Williamon, 2002).

Once long-term memories are stored, it is the performer's objective to develop cues to be used during a performance. The challenge of maintaining long-term musical memory is to keep the associations alive between the memory and its corresponding cue (Snyder, 2002). Memory cues can change over time and it is vital to select cues based on ideas that should be communicated to the audience (Chaffin, 2002).

To prepare for memorization work, one must free themselves from tension. Memorization requires an alert mind and an unwavering determination to commit a piece to memory (Cooke, 1948). When a pianist prepares to memorize, their minds should be ready to choose cues that will remain at the forefront of their minds. Retentiveness depends on the impact of the initial impression of a new piece and the degree to which repetition is used (Hughes, 1915). Understanding the memorization process aids in the application of the different types of memory to one's playing. 


\section{Types of Memory}

There are four types of memory that pianists employ: kinesthetic, visual, auditory, or aural, and analytical memory. There is not a superior way to memorize a piece, which means every pianist must find his/her own method to securely memorize a given selection (Hughes, 1915). Gordon found that theoretical or structural analysis can be used with kinesthetic memory to ensure a successful performance (Gordon, 1995). The research shows contradictory results on the most successful type of memory, but most find that the development and application of each type of memory is essential, because each type of memory brings with it a different set of benefits and risks.

\subsection{Kinesthetic Memory}

Kinesthetic memory is, in essence, touch memory or muscular memory. When using this method, pianists memorize both the feel of the piano keys, and the way their fingers move to execute a passage. It is thought to be the weakest type of memory by concert pianists due to the inertia and hidden unconsciousness of the muscular movement. Ford (1996) found that those pianists who rely on kinesthetic memory tend to make more frequent memory lapses. From Imreh and Crawford's survey (2002) of accomplished performing artists, kinesthetic memory was rated the most insecure of the four types. Since kinesthetic memory is not trustworthy, there must be another memory type that is more suitable for pianists.

\subsection{Visual Memory}

Visual, or photographic, memory presents itself in two ways: it can either refer to the notes on the page, in which the page is used to encode memory; or, the pianist can use the keyboard itself as a visual cue (Imreh \& Crawford, 2002). Of those pianists who use the page as their cue, there are very few who can visualize the entire page of music. Since much of the detailed information printed on the page is missing, the performance may sound incomplete. Visual memory is not one that occurs automatically, and therefore, it is not taken for granted by pianists; they either have it or they do not. Visual memory was found to be depended on by most pianists. Of those pianists surveyed by Imreh and Crawford (2002), keyboard visual memory was never used as the primary method of memorization. Coupling visual memory with auditory may encourage the inclusion of more details.

Ford (1996) believes that the use of auditory memory is essential to bring across the expression within the music. Jorge Bolet said that his memorization is almost done completely by ear (Noyle, 1987). Many pianists who memorize entirely by ear claim that their memorization is automatic or natural (Imreh \& Crawford, 2002).

"Natural memory is usually associated with what is known as absolute pitch, though one with this gift is frequently in too much of a hurry to make the best use of it" (Mackinnon, 1944). Pianists who memorize their music "automatically" participate in an unknowing experience that only requires passive repetitions and limited understanding (Jordan-Anders, 1990). This can be very dangerous because, if the pianist forgets what it is that he or she is used to hearing, they might be less able to continue, as would a pianist who had consciously memorized the music using a combination of methods (Mackinnon, 1944). Chappell (1999) warns students against memorizing passively because it can lead to a panic if the automatic memory responses fail.

Chaffin (2002) believes that those who believe that memory is automatic do not understand the complete picture.

First, the formal structure of classical music, with its divisions and subdivisions into movement, sections, themes, and motives, provides a ready-made hierarchical organization... Second, some understanding of the formal structure seems essential if a performer is to avoid confusing the different repetitions of highly similar thematic material that form the basis for the formal structure of any piece... Third, almost all of the pianists in Imreh and Crawford's survey on memorization admit to knowing the formal structure, if not to memorizing it.

Chaffin's assumption of automatic memory not being entirely automatic, points to analytical memory assisting aural and automatic memory in the formation of performance cues.

\subsection{Analytical Memory}

Analytical, or structural, memory reveals itself in the analyzing of the piece's formal structure and using that structure to guide one's practice. Chaffin and Imreh's (1997) research shows that analytical memory is more closely related to other expert memoirists than the other types of memory previously mentioned. Imreh analyzed the formal structure of the piece, and in her practice, increased the rate with which she could activate her organizational retrieval cues. She organized her practice by the different sections within the formal structure and an analysis of her practice showed that she was more likely to start and stop at a boundary of those previously determined structures. Shockley observed that "memorization that is based on awareness of musical patterns and 
structure rather than on rote repetition can promote a more secure performance and foster an efficient stimulating approach to learning" (Shockley, 1986).

In Sloboda's study (1985), he examined an idiot savant's memorization as it compared to that of a professional pianist. He sought to find evidence that an idiot savant used structural knowledge to memorize music. If the idiot savant used structural memory, then his errors would uphold the harmonic and melodic structures. He found that the idiot savant's playing preserved the harmonic movement, at the expense of non-chord tones, which provided "informal evidence that supports the view that his skill is essentially structure based, and not a more primitive form of mimicry" (Sloboda, 1985).

Williamon and Valentine (2002) studied the changes in the use of hierarchically organized retrieval structures that occurred as musicians gained in ability and experience. They found that the use of hierarchical structures used to organize practice and function as retrieval cues as they relate to the level of skill are:

(1) The overall use of structural bars in starting and stopping practice segments increased with ability level,

(2) The use of structural bars in starting and stopping practice increased with stage of practice, and (3) the early use of structural bars to guide practice was correlated with quality of performance (Williamon \& Valentine, 2002).

Clarke (1988) found that the extent to which structure is used corresponds to the significance given to various phrase boundaries lying near, or at, the place in the music in which the player is located. This suggests that those sections that are practiced prior to performance directly influence the sectional cues activated during performances. There are pianists who practice analytical memory away from the piano. Many pianists, such as Dichter, de Larrocha and Gebhard, reported that they practiced their pieces silently in their mind (Imreh \& Crawford, 2002). This sort of practice should supplement and be practiced along with other types of memorization systems. Even though the conceptual memory is highly recommended by performing artists, there is no substitute for using a variety of methods to solidify one's memory.

\section{Pedagogical Implications from the Literature}

Teachers should reevaluate their teaching strategies to allow more time to teach and prepare students for the hardships and joys of memorization (Chappell, 1999). Also, some of the literature given to students will have to be shorter, less difficult pieces which should be used to practice the process of memorization with students. Memorization should be taught as an intellectual process, on which requires the recognizing of musical patterns, the repetition of a passage numerous times correctly, the use of small passages to memorize (Jacobson, 1992), and as a musical process, allowing the phrases and character of the music help solidify the memorization.

Jordan-Anders (1990) believes that through analyzing a piece, thoughtful practice can be stimulated and encouraged. Active and thoughtful practices are made more comfortable, if a knowledge base is set in music theory, history, harmony and formal analysis (Imreh \& Crawford, 1996). By analyzing the form of the piece prior to performance, "a pianist playing by memory gains confidence by consciously finding musical landmarks such as double bars, key shifts, new theme entrances and other important structural points" (Street, 1987, p. 32). The knowledge gained from analytical memory can be very useful in performance, and is one that must be taught because it is not an automatic process.

There are many memoirists who believe that memorization is not just the remembering of data. Most musicians try to memorize music through entirely intellectual and dispassionate processes, which interrupts the natural memorization process. Musicians should let the emotions of the music create the memory (Penneys, 1992). It is important to understand and share with students that memorization is part of our art, and as such, memorization should be used as a vehicle to further the expression inherit within the music.

Some teachers assume that student memory slips are inevitable; this does not necessarily have to be the case. Memory slips can be a result of a number of things such as poor habits in learning the piece, repertoire that is too challenging, and ear training or aural skills deficiencies (Jacobson, 1992). The deficiencies in training might not appear until much later in the student's learning. If a good student has not experienced any memory slips thus far in their training, it does not prove that the student is memorizing correctly. "Unfortunately, at some time this student probably will be faced with a memory problem, unless the teacher has discussed memory procedures and encourages him to accomplish memory practice before every performance" (Magrath, 1983, p. 16).

It is imperative that teachers continue their own memory work. When a teacher memorizes a piece, they could discover new methods in memorization that can aid in the teaching of their students (Jordan-Anders, 1990). If teachers rely on only one method for memorization, they will be less successful in teaching their students to memorize effectively. It is imperative that students and teachers alike understand how they memorize to examine 
whether one method is relied upon to heavily. "There is no substitute for practice, but understanding different ways to memorize will generally improve the result. After that, choosing the right combination of methods will help students memorize with less effort and better results" (Ford, 1996, p. 26).

\section{Further Research}

The research exploring memorization is not yet complete. It seems imperative to spend more time investigating the effect that memorization has on musical performances, both the mental processes during the performance by the performer and the effect of memorization as perceived by the audience. Another avenue of memorization that must be analyzed is the pressure placed upon the individual responsible for memorizing a performance. The last area of research that has not yet been explored in detail is the idea that those performers who memorize their music have a better understanding of the piece. Does a performer who memorizes a performance understand the form, expressive elements, and overall impression better than one who plays with the music? These questions have not yet been examined in detail and would provide compelling arguments for or against memorization for pedagogues and performers with an interest in memorization.

\section{Conclusion}

Memorization is a necessary part of pianists' lives, and as such, it is important to teach our students how to memorize correctly. Understanding the function, types and reasons for memorization are the most important ideas to teach students. If teachers are to teach students how to memorize, they must be fully versed in the different types of memory and strategies so that they are able to show their students a variety of methods to conquer memory. By assessing student's progress through games and other activities, memory slips can be avoided and even eliminated. Students should be tested frequently and in low pressure situations before they are required to perform for an audience by memory. If these conditions are met, memory slips should be removed. Indeed, memorization is a challenge for all pianists, but it is one that can be conquered.

\section{References}

Aiello, R., \& Williamon, A. (2002). Memory. In R. Parncutt, \& G. McPherson (Eds.), The Science \& Psychology of Music Performance: Creative Strategies for Teaching and Learning (pp. 167-181). New York: Oxford University Press. http://dx.doi.org/10.1093/acprof:oso/9780195138108.003.0011

Anderson, J. R. (1976). Language, memory, and thought. Mahwah, N. J.: Lawrence Erlbaum Associates, Publishers. http://dx.doi.org/10.1080/135467897394310

Chaffin, R. (2002). Expert memory. In R. Chaffin, G. Imreh, \& M. Crawford (Eds.), Practicing perfection: Memory and piano performance (pp. 66-72). Mahwah, N. J.: Lawrence Erlbaum Associates, Publishers.

Chaffin, R., \& Imreh, G. (1997). Pulling teeth and torture: Musical memory and problem solving. Thinking and Reasoning, 3, 315-336.

Chappell, S. (1999). Developing the complete pianist: A study of the importance of the whole-brain approach to piano teaching. British Journal of Music Education, 16(3), 253-262. http://dx.doi.org/10.1017/S0265051 799000340

Clarke, E. F. (1988). Generative principles in music performance. In J. A. Sloboda (Ed.), Generative processes in music (pp. 1-26). Oxford: Clarendon Press. http://dx.doi.org/10.1093/acprof:oso/9780198508465.003.0001

Cooke, J. F. (1948). How to memorize music. Philadelphia: Theodore Presser Co.

Ford, J. (1996). Many ways to memorize. Clavier, 35(3), 24-26.

Gordon, S. (1995). Etudes for piano teachers: Reflections on the teacher's art. New York: Oxford Univ. Press.

Hughes, E. (1915). Musical memory in piano playing and piano study. Musical Quarterly, 1(4), 592-603. http://dx.doi.org/10.1093/mq/I.4.592

Imreh, G., \& Chaffin, R. (1996). Understanding and developing musical memory: The views of a concert pianist and a cognitive psychologist. American Music Teacher, 46(3), 20-24.

Imreh, G., \& Crawford, M. (Eds.). Practicing perfection: Memory and piano performance (pp. 26-65). Mahwah, New Jersey: Lawrence Erlbaum Associates Publishers.

Jacobson, J. M. (1992). Memorize and remember. American Music Teacher, 41(4), 16-19.

Jordan-Anders, L. (1990). Stamp out memory-by-default. Clavier, 29(5), 32-36.

Mackinnon, L. (1944). Music by heart. New York: Oxford University Press. http://dx.doi.org/10.2307/923122 
Magrath, J. (1983). Nerves, memory, and pianos. American Music Teacher, 33(1), 14-18.

Marks, V. (n. d.). Memory Games for Young Students. Handout from lecture on memorization at Bowling Green State University.

Montparker, C. (1998). A pianist's landscape. Portland, Oregon: Amadeus Press.

Montparker, C. (2001). Carillon (memorizing music). Clavier, 40(10), 47.

Noyle, L. (1987). Pianist's on Playing: Interviews with Twelve Concert Pianists. The Scarecrow Press Inc.

Penneys. R. (1992). Motion and emotion. Clavier, 31(7), 16-19.

Shockley, R. (1986). A new approach to memorization. Clavier, July-August, 20-23.

Sloboda, J. (1985). An exceptional musical memory. Music Perception, 3(2), 155-170.

Snyder, B. (2000). Music and memory: An introduction. Cambridge, Massachusetts: The MIT Press. http://dx.doi.org/10.1093/oxfordhb/9780199298457.013.0010

Street, E. (1987). Bridging the gap between sight reading \& memorizing. American Music Teacher, 37(2), 32-33.

Williamon, A. (1999). The value of performing from memory. Psychology of Music, 27, 84-95. http://dx.doi.org/10.1177/0305735699271008

Williamon, A., \& Valentine, E. (2002). The role of retrieval structures in memorizing music. Cognitive Psychology, 44, 1-32. http://dx.doi.org/10.1006/cogp.2001.0759

\section{Appendix}

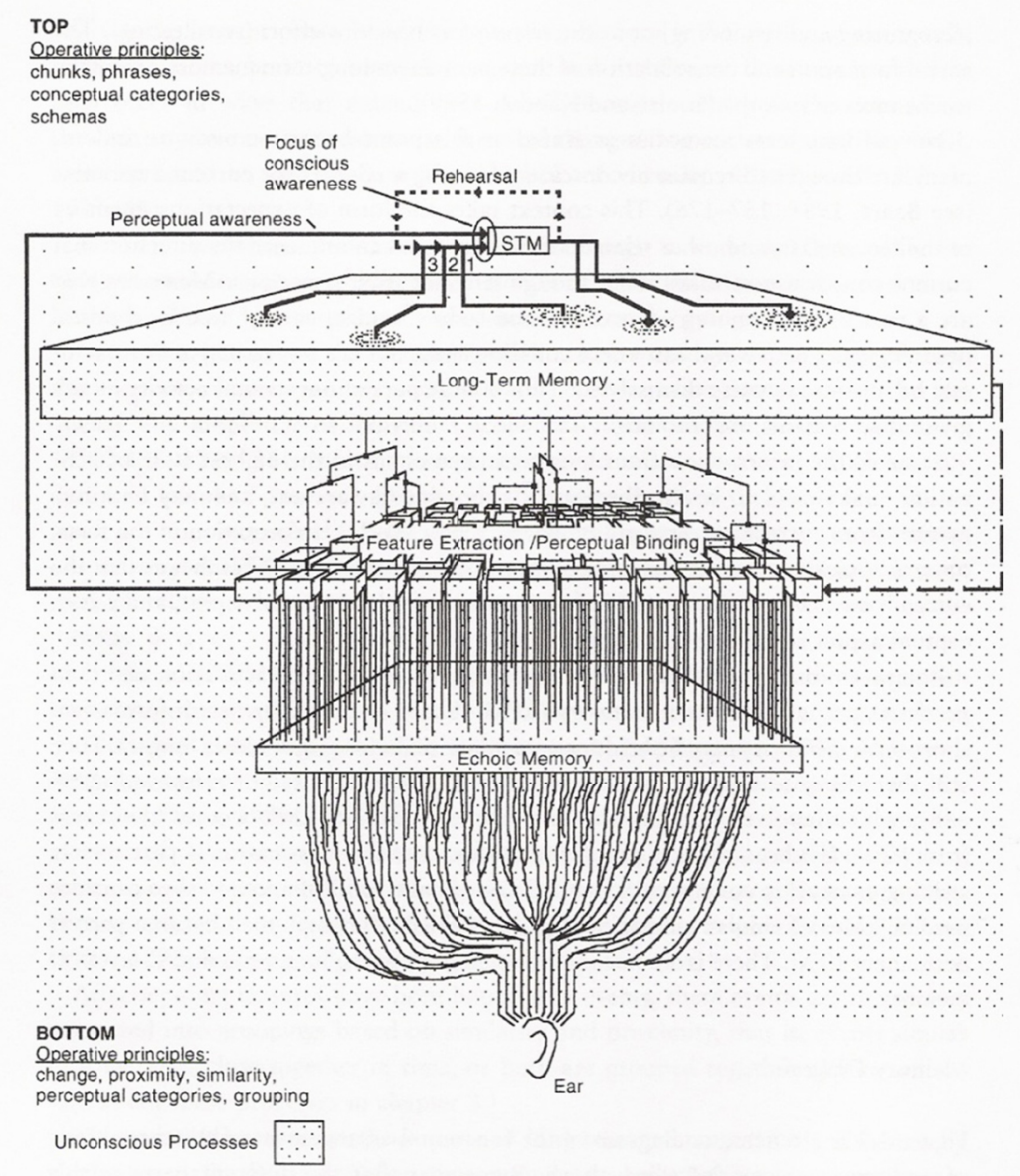

(Snyder, 2000, p. 5) 


\section{Copyrights}

Copyright for this article is retained by the author(s), with first publication rights granted to the journal.

This is an open-access article distributed under the terms and conditions of the Creative Commons Attribution license (http://creativecommons.org/licenses/by/3.0/). 